\title{
First Case of Deep Hypothermic Circulatory Arrest in Senegal (West Africa): Congenital Heart Disease Management
}

\author{
Abdel-Kémal Bori Bata ${ }^{1,2}$, Amadou Gabriel Ciss², Baba Ibrahima Diarra ${ }^{2}$, Momar Sokhna Diop ${ }^{2}$, \\ Papa Salmane Ba ${ }^{2}$, Pape Amath Diagne ${ }^{2}$, Ndeye Fatou Sow ${ }^{2}$, Magaye Gaye ${ }^{2}$, Souleyman Diatta ${ }^{2}$, \\ Mohamed Leye ${ }^{3}$, Etienne Birame Sene ${ }^{4}$, Papa Adama Dieng ${ }^{2}$, Assane Ndiaye ${ }^{1}$, \\ Mouhamadou Ndiaye ${ }^{1}$ \\ ${ }^{1}$ Department of Pediatric Surgery Child and Mother University Hospital, Cotonou, Benin \\ ${ }^{2}$ Department of Thoracic and Cardiovascular Surgery FANN University Hospital, Cheikh Anta Diop University, Dakar, Senegal \\ ${ }^{3}$ Department of Cardiology FANN University Hospital, Cheikh Anta Diop University, Dakar, Senegal \\ ${ }^{4}$ Department of Anesthesiology FANN University Hospital, Cheikh Anta Diop University, Dakar, Senegal \\ Email address: \\ bbak@live.fr (Abdel-Kémal B. Bata), cissgaby@yahoo.fr (A. G. Ciss), diarrabi85@yahoo.fr (B. I. Diarra), \\ momarsokhna08@yahoo.fr (M. S. Diop), mansalb@yahoo.fr (P. S. Ba), diagnepapaamath@gmail.com (P. A. Diagne), \\ zenefes@gmail.com (N.F. Sow), mgaye99@yahoo.fr (M. Gaye), soul.diatta@yahoo.fr (S. Diatta), leyemohamed@gmail.com (M. Leye), \\ biramsene@hotmail.com (E. B. Sene), padiengsala@yahoo.fr (P. A. Dieng), lazanat@yahoo.fr (A. Ndiaye), \\ mondiaye@orange.sn (M. Ndiaye)
}

\section{To cite this article:}

Abdel-Kémal Bori Bata, Amadou Gabriel Ciss, Baba Ibrahima Diarra, Momar Sokhna Diop, Papa Salmane Ba, Pape Amath Diagne, Ndeye Fatou Sow, Magaye Gaye, Souleyman Diatta, Mohamed Leye, Etienne Birame Sene, Papa Adama Dieng, Assane Ndiaye, Mouhamadou Ndiaye. First Case of Deep Hypothermic Circulatory Arrest in Senegal (West Africa): Congenital Heart Disease Management. International Journal of Cardiovascular and Thoracic Surgery. Vol. 4, No. 5, 2018, pp. 39-42. doi: 10.11648/j.ijcts.20180405.11

Received: October 25, 2018; Accepted: December 21, 2018; Published: January 29, 2019

\begin{abstract}
Background: Deep hypothermic circulatory arrest (DHCA) is an extracorporeal circulation (EC) technique used to correct complex congenital cardiac lesions. This technique ensures excellent operating conditions while reducing consequences of organ ischaemia, particularly of the brain. Griepp was the first to demonstrate in 1975, that the technique offered a practical and safe approach for aortic arch surgery. Case Report: Authors aim at reporting the practical conduct of DHCA's first case performed in Dakar (Senegal) on a 30- month-old patient diagnosed with supracardiac total anomalous pulmonary venous connection (TAPVC). The cooling had started 8 minutes after CPB was initiated and continued while the surgeon dissected the pulmonary veins, the collector, and the innominate vein. After the establishment and the starting up of the cardiopulmonary bypass, circulatory arrest was performed at $18^{\circ} \mathrm{C}$ with 32 minutes of arrest time. The anastomosis between collector and posterior of the left atrium was achieved during a circulatory arrest. In the immediate postoperative period, patient showed episodes of hypothermia and biological bleeding. During her hospitalization, the patient developed a lung infection and PAH crisis, kept under control with antibiotic, diuretics, oxygen and sildenafil. Neurological, kidney, metabolic or ionic complications have not been observed. The patient stayed at the hospital for 32 days. Conclusion: DHCA technique is a common practice in developed countries. However, it can also be carried out in West Africa as evidenced by this clinical case. This prowess testifies a strengthening of our skills in EC technique; and also, the possibility of correcting complex congenital cardiac lesions.
\end{abstract}

Keywords: Deep Hypothermic, Circulatory Arrest, Congenital Cardiac Lesions 


\section{Introduction}

Deep hypothermic circulatory arrest (DHCA) is a technique used to repair complex congenital cardiac lesions that requires aortic arch or pulmonary vein repair. This technique ensures excellent operating conditions while reducing consequences of organ ischaemia, particularly of the brain. Since the introduction of DHCA in early 1960s, Griepp was the first to demonstrate in 1975, that the technique offered a practical and safe approach for aortic arch surgery. Since then, this technique has been increasingly used in centers with expertise on open heart surgery for infants, children, and adults. Most patients tolerate 30 minutes of circulatory arrest at $18^{\circ} \mathrm{C}$ without significant neurological damage. Above 40 to 60 minutes, brain lesions frequency increases significantly. DHCA is an unusual cardiopulmonary bypass (CPB) technique in West Africa where cardiac surgery is virtually non-existent in most countries. This report aims at describing a practical conduct of the first case of DHCA that has been performed for surgical correction of TAPVC at the Pediatric Cardiac Surgery Center of the University Hospital of Fann in Senegal. [1-4]

\section{Case Report}

MD was a 30-month-old female patient diagnosed with supracardiac TAPVC. Her previous medical history revealed no abnormality. The physical examination of the patient identified failure to thrive (weight $=10 \mathrm{~kg}$, height $=82 \mathrm{~cm}$, $\mathrm{BSA}=0.47, \mathrm{BMI}=14.8$ ), pulmonary systolic murmur and accentuated second heart sound. The electrocardiogram was in regular sinus rhythm with right ventricular hypertrophy. The chest $x$-ray identified cardiomegaly (cardiothoracic ratio $=0.7$ ) and indirect signs of pulmonary arterial hypertension (PAH). The echocardiography identified:

1. supra cardiac TAPVC with a partially stenosed collector (mean gradient $=9 \mathrm{mmHg}$ ) draining into the innominate vein; an atrial septal defect (ASD), ostium secundum type measuring $6 \mathrm{~mm}$ and shunting from left to right;

2. Right cavities dilatation, good biventricular function: $\mathrm{LVEF}=73 \%$

3. PAH with SPAP (systolic pulmonary arterial pressure) $=$ $110 \mathrm{mmHg}$

The angioscanner or cardiac magnetic resonance imaging was not performed and the patient had no preoperative biological abnormality. She did not benefit from any sedative premedication or administration of corticosteroids prior to surgery. The monitoring was performed by an invasive measurement of the radial arterial pressure and the central venous pressure (internal jugular). The central temperature was measured at the rectal and nasopharyngeal sites. A transœsophageal echocardiography was set up as such: no cerebral monitors and no pulmonary arterial catheter. In addition, sevoflurane, propofol, norcuron and fentanyl were used as anesthetic. The anticoagulation was performed with heparin at 3500 IU parenterally and 2000 IU in the priming. The ACT (Activated clotting time) before CPB was 700 seconds (sec). The anti-fibrinolytic agent used was tranexamic acid: a bolus of $300 \mathrm{mg}$ then $600 \mathrm{mg}$ in continuous perfusion. A 50-mg of hydrocortisone was administered prior to CPB initiation. The cell-saver was installed systematically. The CPB was carried out with S5 SORIN equipped with a roller pump. The related elements that were connected to the $\mathrm{CPB}$ circuit are: conventional ultrafiltration, an inline infusion bag. The size of the cardiotomy reservoir was $1200 \mathrm{ml}$; and heparin-coated circuits were used. The priming was composed of $300 \mathrm{ml}$ of homologous blood, $250 \mathrm{ml}$ of FFP (fresh frozen plasma). During CPB, $500 \mathrm{ml}$ of ringer, $250 \mathrm{ml}$ of FFP, $25 \mathrm{ml}$ of Mannitol (20\%) were perfused. (Figure 1)

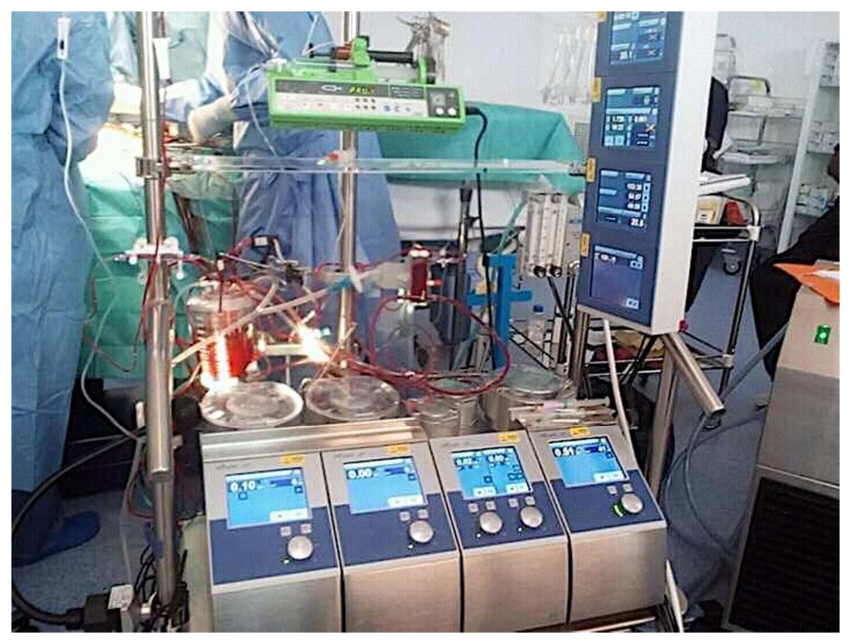

Figure 1. Assembly of $C P B$ circuit for the DHCA.

The CPB was established between an aortic cannula of 12 French (F) and two vena cava cannulas of $16 \mathrm{~F}$ each; connected to heparin-coated arterial and venous lines of $1 / 4$ inch each. A left discharge cannula (12 F) at the infundibulum. The cooling had started 8 minutes after CPB was initiated and continued while the surgeon dissected the pulmonary veins, the collector, and the innominate vein. Additional cerebral cooling was achieved by coating ice packed around the head. At the nasopharyngeal temperature of $28^{\circ} \mathrm{C}$, aortic cross clamping was followed by cold blood cardioplegia. Circulatory arrest was performed at $18^{\circ} \mathrm{C}$ followed by exsanguination. The anastomosis between collector and posterior of left atrium was achieved during a circulatory arrest. ASD was partially closed during rewarming.

Circulatory arrest time was 32 minutes (min) and hypothermic perfusion time prior to rewarming initiation was $10 \mathrm{~min}$. The amount of blood stored in the inline infusion bag during the circulatory arrest was $400 \mathrm{ml}$; this blood was transfused during rewarming. The CPB flow during mild to moderate hypothermia varied between $1.08-1.38 \mathrm{~L} / \mathrm{min} / \mathrm{m}^{2}$ and varied between $0.73-0.77 \mathrm{~L} / \mathrm{min} / \mathrm{m}^{2}$ in deep hypothermia. The mean arterial pressure varied between 30 and $60 \mathrm{mmHg}$. The resumption of cardiac activity was in sinus bradycardia regularized by external electrical stimulation. CPB time was $197 \mathrm{~min}$ and that of clamping $66 \mathrm{~min}$; CPB assistance lasted 31 min while rewarming changed temperature up to $36.5^{\circ} \mathrm{C}$. The amount of hemofilter blood was $240 \mathrm{ml}$. The biological data during CPB were: ACT $=762-999 \mathrm{sec}$; hematocrit $=$ 
$21 \%-25 \% ; \mathrm{pH}=7.46-7.57 ; \mathrm{PaO}_{2}=304-368 \mathrm{mmHg} ;$ $\mathrm{PaCO}_{2}=29-30 \mathrm{mmHg}, \mathrm{SaO} 2=100 \%, \mathrm{SvO} 2=78 \mathrm{mmHg}$; diuresis $=220 \mathrm{ml}$. The biological data at the exit of CPB were: $\mathrm{pH}=7.58 ; \mathrm{PaCO}_{2}=25 \mathrm{mmHg} ; \mathrm{PaO}_{2}=269 \mathrm{mmHg}$; hematocrit $=26 \%$. There were no ionic and metabolic disorders during or after CPB. Protamine was administered at a dose of $7000 \mathrm{IU}$. An amount of $150 \mathrm{ml}$ of blood was collected in the cell-saver; and transfused to the patient.

In the immediate postoperative period, patient showed episodes of hypothermia and biological bleeding $>3$ $\mathrm{ml} / \mathrm{kg}$ /hour; which required an administration of $200 \mathrm{ml}$ of FFP and tranexamic acid. Postoperative PAH (sPAP $=77$ mmhg) was managed by the administration of sildenafil (90 $\mathrm{mg} /$ day). The patient was extubated at $21^{\text {st }}$ postoperative hour. She had marked an anemia of $9 \mathrm{~g} / \mathrm{dl}$ and thrombocytopenia at $120,000 / \mathrm{mm}^{3}$, but did not present any neurological, kidney, metabolic or ionic complications. The patient was kept on intensive care observation for 7 days. However, during her stay at the hospital, she developed a lung infection and $\mathrm{PAH}$ crisis, kept under control with antibiotic, diuretics, oxygen and sildenafil. The length of her stay in the hospital was 32 days.

\section{Discussion}

Dillard et al. performed corrections of TAPVC using DHCA in 1967. This technique is commonly used in American, European and Asian cardiac surgery centers. However, this technique was implemented for the first time in our cardiac surgery center, indicating a strengthening of EC technical skills. There is no literature on the use of DHCA in the correction of congenital cardiac lesions reported by cardiac surgery centers in west Africa. [1,5]

We did not use any specific premedication. Although the use of corticosteroids (6- $8 \mathrm{~h}$ before surgery) may decrease the release of inflammatory cytokines and preventing lysosomal breakdown during hypothermia. Despite a limited evidence of outcome benefit, neurological monitoring is routinely used in many centers. Our Center doesn't dispose of a cerebral monitoring device as well as a centrifugal pump the latter must be preferentially used to reduce haemolysis, maintains the leucocyte count, and preserves platelet function. [3]

Theoretically, avoiding volatile agents, which uncouple cerebral blood flow from cerebral metabolism, may confer some benefit. In a recent survey, $83 \%$ of anesthetists used agents as pharmacological neuroprotection during DHCA: thiopental (59\%), propofol (29\%) and others in $48 \%$ of cases, most commonly corticosteroids However, thiopental is commonly used for children. The optimal strategy for protecting the brain remains controversial [6-9].

In our case, despite haemodilution, the minimum hematocrit was $21 \%$. Haemodilution, typically to a haematocrit of $20 \%$, improves flow in the microcirculation during hypothermia. Excessive haemodilution significantly reduces oxygen carrying capacity and causes tissue ischaemia. Priming to blood as in our patient, limits excessive haemodilution and improves brain recovery after circulatory arrest. [3, 10-11]
Circulatory arrest time was 32 minutes (min). Indeed, the literature reports a mean time of $32 \mathrm{~min}$ (range, 28 to $37 \mathrm{~min}$ ) especially towards the correction of TAPVC. However, it is on average $20 \mathrm{~min}$ (range, 3 to 52) in the correction of various complex congenital cardiac lesions. Circulatory arrest is typically undertaken at $18-20^{\circ} \mathrm{C}$ and a range of safe periods for DHCA have been reported at this temperature. Hypothermic perfusion should be maintained for 10-20 min before initiation of rewarming. This would reduce the risk of increasing intracranial pressure. The temperature variation after rewarming from DHCA is associated with survival and neurologic outcome. $[3,4,10,12,13]$

The incidence of acute neurological complications after DHCA is on the order of $1-25 \%$. The main complication of our patient was a postoperative bleeding. Coagulopathic haemorrhage remains a significant cause of morbidity and early death after DHCA. In most centers, thromboelastography during surgery and laboratory tests of coagulation are used to guide early, aggressive correction of thrombocytopenia and clotting factor deficiency. This strategy appears to reduce the amount of blood derivatives administered. [3, 14-16]

\section{Conclusions}

DHCA technique is a common practice in developed countries. However, it can also be carried out in West African country as evidenced by this clinical case. This prowess testifies a strengthening of our skills in EC technique; and also, the possibility of correcting complex congenital cardiac lesions.

\section{Conflict of Interest}

All the authors hereby disclose that they do not have any potential conflicts of interest to be mentioned. Funding: This research received no specific grant from any funding agency in the public, commercial or not-for-profit sectors.

\section{References}

[1] Rimmer L, Fok M, Bashir M. The History of Deep Hypothermic Circulatory Arrest in Thoracic Aortic Surgery. Aorta. 2014; 2(4):129.

[2] Sainathan S, Monge M, Eltayeb O. Successful Repair of a Ruptured Mycotic Aortic Aneurysm in a Pediatric Patient with Deep Hypothermic Circulatory Arrest. The American Surgeon. 2018; 84 (2): 77-79.

[3] Conolly S, Arrowsmith JE, Klein AA. Deep hypothermic circulatory arrest. Continuing Education in Anaesthesia, Critical Care \& Pain. 2010; 10 (5): 138-42.

[4] Elassal AA, Debis RS, Faden MS, Alqari AH, Abdulaziz MA, Al Radi OO. Outcomes of deep hypothermic circulatory arrest in pediatric cardiac surgery: A single center experience. Journal of the Egyptian Society of Cardio-Thoracic Surgery. 2016; 24 (3): 228-31 
[5] Nwiloh JO, Oludara MA, Adebola PA. Heart surgery practice in Sub Saharan Africa: single Nigerian institutional midterm results and challenges. World Journal of Cardiovascular Surgery. 2014; 4 (03): 35.

[6] Svyatets M, Tolani K, Zhang M, Tulman G, Charchaflieh J. Pharmacological agents as cerebral protectants during hypothermic circulatory arrest. J Cardiothorac Vasc Anesth. 2010; 24 (4): 644-55.

[7] Ross FJ, Joffe D, Latham GJ. Perioperative and anesthetic considerations in total anomalous pulmonary venous connection. In Seminars in cardiothoracic and vascular anesthesia. Sage CA: Los Angeles, CA: SAGE Publications. 2017; 21: 138-144.

[8] Schlunt ML, Brauer SD. Anesthetic management for the pediatric patient undergoing deep hypothermic circulatory arrest. In: Seminars in cardiothoracic and vascular anesthesia. Sage CA: Thousand Oaks, CA: Sage Publications. 2007; 11: 16-22.

[9] Porapakkham P, Porapakkham, P. Cerebral Protection in Aortic Arch Surgery: Clinical Outcomes from Single Institute. Journal Of The Medical Association Of Thailand, 2018; 01 (5): 621.

[10] Rungatscher A, Luciani GB, Linardi D, Milani E, Gottin L, Walpoth B, et al. Temperature variation after rewarming from deep hypothermic circulatory arrest is associated with survival and neurologic outcome. Therapeutic hypothermia and temperature management. 2017; 7 (2): 101-106.
[11] Urbanowicz TK, Budniak W, Buczkowski P, Perek B, Walczak $\mathrm{M}$, Tomczyk J, et al. Brain activity monitoring by compressed spectral array during deep hypothermic circulatory arrest in acute aortic dissection surgery. Kardiochir Torakochirurgia Pol. 2014; 11 (4): 409-13

[12] Jinghao Z, Botao G, Zhiwei X, Jinfeng L. The research on operation of obstructed total anomalous pulmonary venous connection in neonates. Scientific World Journal. 2014: 576569.

[13] Shen I, Ungerleider RM. Repair of supracardiac total anomalous pulmonary venous return. Operative Techniques in Thoracic and Cardiovascular Surgery. 2001; 6: 8-11.

[14] Elassal AA, Debis RS, Faden MS, Alqari AH, Abdulaziz MA, Al Radi OO. Outcomes of deep hypothermic circulatory arrest in pediatric cardiac surgery: A single center experience. Journal of the Egyptian Society of Cardio-Thoracic Surgery, 2016; 24 (3): $228-231$.

[15] Lee Y, Cho JY, Kwon OY, Jang WS.. Outcomes of surgery for total anomalous pulmonary venous return without total circulatory arrest. The Korean journal of thoracic and cardiovascular surgery. 2016; 49 (5), 337.

[16] Geube M, Sale S, Svensson L. Con: Routine Use of Brain Perfusion Techniques Is Not Supported in Deep Hypothermic Circulatory Arrest. J Cardiothorac Vasc Anesth. 2017; 31 (5): 1905-1909. 